\title{
Paradigmas da educação financeira no Brasil*
}

\author{
José Roberto Ferreira Savoia** \\ André Taue Saito*** \\ Flávia de Angelis Santana****
}

SUMÁRIO: 1. Introdução; 2. Literatura internacional; 3. Experiência internacional; 4. Educação financeira no Brasil; 5. Considerações finais.

SUMMARY: 1. Introduction; 2. International literature; 3. International experience; 4. Financial education in Brazil; 5. Final remarks.

PALAVRAs-CHAVE: educação financeira; paradigmas; experiência internacional; política de educação.

KEY wORDs: financial education; paradigms; international experience; educational policy.

Este artigo propõe cinco ações que auxiliam no engajamento dos agentes públicos e privados no programa de educação financeira. Para alcançar tal finalidade, foi realizado um levantamento bibliográfico e documental, de modo a oferecer respaldo teórico qualitativo à descrição apresentada. $\mathrm{O}$ artigo inicia com a contextualização e a relevância do assunto. Aborda visões de autores internacionais sobre o tema, aprecia o estágio atual nos Estados Unidos, nos países do Reino Unido, em outros países da OCDE e no Brasil. Constata que, no país, ainda há um tratamento incipiente dessa questão, determinado pelo limitado conhecimento e reduzida experiência

\footnotetext{
* Artigo recebido em abr. e aceito em out. 2007.

** Administrador, mestre e doutor em administração pela FEA/USP; pós-doutorado pela Columbia University. Professor doutor na FEA/USP e adjunct professor na Columbia University. Endereço: Av. Prof. Luciano Gualberto, 908, sala G-116 - CEP 055508-010, São Paulo, SP, Brasil. E-mail: jrsavoia@usp.br.

$* * *$ Administrador de empresas pela FEA/USP, MBA em gestão financeira e risco pela Fipecafi, mestrando em administração de empresas (finanças) na FEA/USP. Endereço: Av. Prof. Luciano Gualberto, 908, sala G-116 - CEP 055508-010, São Paulo, SP, Brasil. E-mail: saito@usp.br.

$* * * *$ Jornalista pela Unesp e mestranda em história social pela USP. Endereço: Av. Prof. Luciano Gualberto, 908, sala G-120 - CEP 055508-010, São Paulo, SP, Brasil. E-mail: katiafas@hotm ail.com.
} 
dos agentes envolvidos no processo de capacitação financeira. Desse modo, é necessário o fomento de ações por parte do governo, da iniciativa privada e do terceiro setor. Ressalta, ainda, que o papel das instituições de ensino é imprescindível na formação de uma cultura de poupança e na conscientização dos indivíduos para lidar com os instrumentos oferecidos pelo sistema financeiro e atender as suas demandas pessoais.

\section{Paradigms of financial education in Brazil}

This article deals with financial education in Brazil, given its relevance for the society's daily life, and considers five actions to further the involvement of public and private agents in financial education programs. In Brazil, this issue hasn't yet received proper attention, mainly due to the limited knowledge and experience of the players involved in financial education. Thus, it is necessary and urgent that the government, the private sector and the third sector promote activities in this area. The article emphasizes the role of basic, secondary and higher education institutions in developing a savings culture and preparing individuals to deal with the instruments offered by the financial system and to answer their own personal demands.

\section{Introdução}

Educação financeira sempre foi importante aos consumidores, para auxiliálos a orçar e gerir a sua renda, a poupar e investir, e a evitar que se tornem

vítimas de fraudes. No entanto, sua crescente relevância nos últimos anos vem ocorrendo em decorrência do desenvolvimento dos mercados financeiros, e das mudanças demográficas, econômicas e políticas.

(OCDE, 2004:223)

Na sociedade contemporânea, os indivíduos precisam dominar um conjunto amplo de propriedades formais que proporcione uma compreensão lógica e sem falhas das forças que influenciam o ambiente e as suas relações com os demais. O domínio de parte dessas propriedades é adquirido por meio da educação financeira, entendida como um processo de transmissão de conhecimento que permite o desenvolvimento de habilidades nos indivíduos, para que eles possam tomar decisões fundamentadas e seguras, melhorando o gerenciamento de suas finanças pessoais. Quando aprimoram tais capacidades, os indivíduos tornam-se mais integrados à sociedade e mais atuantes no âmbito financeiro, ampliando o seu bem-estar.

Mudanças tecnológicas, regulatórias e econômicas elevaram a complexidade dos serviços financeiros. Mas a insuficiência de conhecimento sobre o assunto, por parte da população, compromete as decisões financeiras cotidia- 
nas dos indivíduos e das famílias, produzindo resultados inferiores ao desejado. Na visão de Braunstein e Welch (2002:1):

Participantes informados ajudam a criar um mercado mais competitivo e eficiente. Consumidores conscientes demandam por produtos condizentes com suas necessidades financeiras de curto e longo prazo, exigindo que os provedores financeiros criem produtos com características que melhor correspondam a essas demandas.

A educação financeira tornou-se uma preocupação crescente em diversos países, gerando um aprofundamento nos estudos sobre o tema. Embora haja críticas quanto à abrangência dos programas e seus resultados, principalmente entre a população adulta, é inegável a importância do desenvolvimento de ações planejadas de habilitação da população.

Nas últimas duas décadas, três forças produziram mudanças fundamentais nas relações econômicas e sociopolíticas mundiais: a globalização, o desenvolvimento tecnológico e alterações regulatórias e institucionais de caráter neoliberal. Isso levou os países desenvolvidos a reduzirem o escopo e o dispêndio de seus programas de seguridade social, ou seja, houve o rompimento do paradigma paternalista do Estado.

\section{As forças propulsoras}

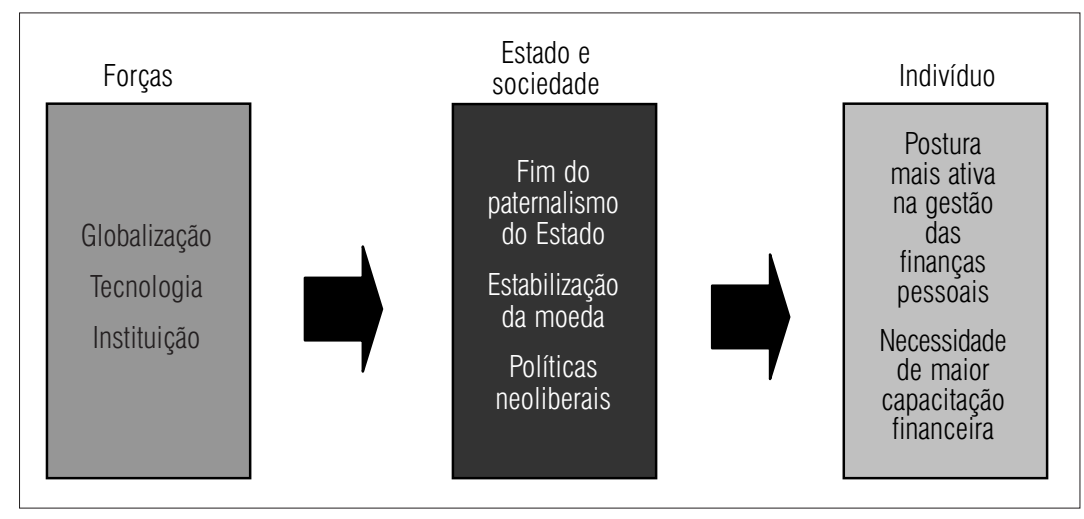

A partir da década de 1990, o Estado brasileiro se transforma e efetua um conjunto de reformas de caráter neoliberal. Sob influência da globalização, ocorreram alterações nas bases tecnológica, produtiva, financeira e educacional, promovendo a reorientação do papel do governo no provimento de servi- 
ços, bens e na proteção aos indivíduos, aí incluídos os seus aspectos sociais e regulatórios.

Outra força propulsora desse novo cenário foi a estabilização da moeda, acarretando a redução da inflação. Em um processo inflacionário, o curtoprazismo é a característica dominante nas decisões financeiras, levando os indivíduos a buscarem mecanismos de defesa do seu poder aquisitivo e do seu patrimônio. A escolha de ativos reais e a procura por liquidez tendem a tornar essas decisões imediatistas e a encurtar o horizonte de planejamento. Desse modo, passa-se a priorizar o consumo, deixando de se criar uma cultura de poupança de longo prazo.

Com a estabilidade, invertem-se as premissas e os prazos são ampliados progressivamente. Os ativos financeiros são valorizados em relação a imóveis, terras e outros bens reais. A transição para esse novo universo não acontece naturalmente, ou seja, é um longo aprendizado, por parte dos indivíduos e das famílias, sobre a nova ótica da gestão financeira de seu patrimônio pessoal.

Paralelamente, começa um processo de crescente transferência de responsabilidades aos indivíduos, até então sob a égide do Estado. A principal delas é a formação da poupança previdenciária, conforme disposto na Emenda Constitucional no 5 , de 1998, que estimula os planos de previdência complementar. Da mesma forma, decisões sobre o financiamento da casa própria, o consumo e o endividamento das famílias são alteradas em função desse cenário, com informações limitadas sobre os instrumentos financeiros à população.

Logo, a principal dificuldade do indivíduo é planejar adequadamente suas ações de longo prazo; é preciso poupar por conta própria para a aposentadoria, não mais provida integralmente pelo Estado. Também é necessário reavaliar as decisões sobre a compra de sua casa própria, e dos bens duráveis, bem como entender as novas modalidades de crédito e dominar a tecnologia disponível para a realização das transações financeiras básicas.

O governo, incapaz de poupar e realizar os investimentos propulsores do crescimento, procurou, nos últimos anos, ampliar a oferta de crédito, para incentivar o consumo de bens e serviços e, assim, aumentar a produção. No entanto, o consumo das famílias não consegue, sozinho, estimular os investimentos, que geram empregos e elevação da renda. Para agravar esse quadro, a população, despreparada para dimensionar o volume de comprometimento do seu orçamento, avança com ímpeto ao crédito fácil e, endividada, busca caminhos para restaurar o seu equilíbrio. O crescimento desorientado do crédito produz a inadimplência. A partir daí, os empréstimos são interrompidos e a economia reduz a sua atividade. Como conseqüência dessas ações, surge um círculo vicioso de expansão e retração do crescimento. 
É evidente que, no Brasil, as autoridades não exercem a função de capacitar a população adequadamente para a tomada de decisões no âmbito financeiro. Organizações privadas, como a Bovespa, e algumas empresas e bancos desenvolvem práticas para minorar essa lacuna e orientar os clientes e usuários dos seus produtos. No entanto, tais ações meritórias são insuficientes para alterar a situação vigente da população, com os produtos destinados às pessoas físicas em franca expansão, conforme a tabela.

\begin{tabular}{|c|c|c|c|c|c|}
\hline \multicolumn{6}{|c|}{ Evolução de produtos de pessoa física - em $\mathrm{R} \$$ mil } \\
\hline Discriminação & 2002 & 2003 & 2004 & 2005 & 2006 \\
\hline Crédito* & 277.063 .975 & 319.026 .745 & 372.114 .269 & 450.836 .096 & 498.887 .834 \\
\hline PGBL & 2.969 .513 & 4.106 .593 & 4.221 .206 & 4.116 .935 & 4.140 .096 \\
\hline VGBL & & & & 11.701 .843 & 15.333 .905 \\
\hline Seguro** & 8.244 .380 & 13.191.102 & 17.670 .273 & 19.978 .985 & 24.716 .859 \\
\hline Previdência aberta & 2.969 .513 & 4.106 .593 & 4.221 .206 & 15.818 .778 & 19.474 .000 \\
\hline $\begin{array}{l}\text { Fonte: Banco Central } \\
\text { * Volume de concess } \\
\text { ** Prêmio total (grup }\end{array}$ & urso livre. & & & & \\
\hline
\end{tabular}

Além disso, ressalta-se que a participação de investidores que utilizam a internet para realizar negócios na Bolsa de Valores de São Paulo (Bovespa) vem crescendo nos últimos anos e, em fevereiro de 2007, o volume de transações por meio do homebroker atingiu novos recordes, alcançando, na média diária, $\mathrm{R} \$ 508,9$ milhões, que correspondem a um número $11,5 \%$ maior do que o registrado em janeiro deste ano.

Por fim, não há como negar que a educação financeira é fundamental na sociedade brasileira contemporânea, visto que influencia diretamente as decisões econômicas dos indivíduos e das famílias. Desse modo, torna-se extremamente necessário ampliar a visão sobre o assunto e discutir os paradigmas que surgem da inserção da educação financeira no contexto político.

\section{Literatura internacional}

A literatura internacional aponta importantes aspectos sobre a evolução, os objetivos, as abordagens, os riscos e os resultados dos programas de educação financeira. A seguir são descritas essas considerações. 


\section{Evolução}

Dolvin e Templeton (2006) apontam a disseminação de programas de educação financeira, na última década, direcionados às comunidades e aos funcionários de empresas.

Bernheim e Garrett (2003) apresentam evidências de que a inclusão de programas de educação financeira nas empresas norte-americanas, a partir da década de 1980, vem estimulando o aumento da adesão aos planos previdenciários, como os 401 (k)s. Além de expandir esses programas em outras organizações, esse resultado contribui para campanhas em defesa da formação de poupança previdenciária, com base no conhecimento financeiro.

\section{Objetivo}

Manson e Wilson (2000), citados por Dolvin e Templeton (2006), defendem que os programas de educação financeira estimulam o desenvolvimento de conhecimento, aptidão e habilidades, formando indivíduos críticos, informados sobre os serviços financeiros disponíveis e preparados para administrar as suas finanças de maneira eficaz. Como recomendações para futuros desenvolvimentos, o estudo realizado por Volpe, Chen e Liu (2006) demonstra que os programas educacionais deverão focar as principais áreas de finanças pessoais, em que os indivíduos têm conhecimento inadequado, incluindo planos de aposentadoria e conceitos básicos de investimentos.

\section{Abordagens}

Serão apresentadas duas abordagens para classificação dos programas de educação financeira. Na primeira delas, os programas são organizados de acordo com o interesse pessoal versus profissional. Na segunda, são divididos segundo o critério de finalidade.

Worthington (2006) afirma que o conhecimento financeiro pode ser enquadrado em duas vertentes: pessoal e profissional. Do ponto de vista pessoal, é atrelado à compreensão da economia e de como as decisões das famílias são afetadas pelas circunstâncias econômicas. Inclui ainda tópicos da gestão de recursos, tais como: orçamento, poupança, investimento e seguro. No âmbito profissional, o conhecimento financeiro é vinculado à compreensão de relatórios financeiros, fluxos de caixa e mecanismos de governança corporativa das empresas. 
Todd (2002), Braunstein e Welch (2002) dividem os programas de educação financeira em três grupos: aquele focado nas finanças pessoais, em assuntos como orçamento, poupança e crédito; outro que oferece treinamento específico para poupança previdenciária e é promovido por empresas; e, finalmente, o relacionado à compra de imóveis.

\section{Riscos}

Fox, Bartholomae e Lee (2005) ressaltam que a ignorância financeira cria vieses potenciais de comportamento, exibidos pelos investidores incultos. Bernheim (1998) conclui que a maior parte dos norte-americanos apresenta lacunas de formação para o gerenciamento de suas finanças pessoais, e suas escolhas em termos de aposentadoria são reflexos dessa deficiência.

Clark e colaboradores (2006) reforçam tal argumento, lembrando que os indivíduos serão cada vez mais responsáveis pela sua renda na aposentadoria e, para que isso ocorra adequadamente, é necessário um certo nível de conhecimento financeiro, de forma a dimensionar os impactos das decisões tomadas.

Ainda segundo Clark e colaboradores (2006), a falta de conhecimento financeiro pode provocar: o adiamento da formação da poupança previdenciária; a incapacidade de tomar decisões corretas de investimento, consumo e poupança; e o aumento da insegurança em relação ao risco e ao retorno dos produtos de investimento.

\section{Resultados}

Mandell (2005) destaca que a inserção dos programas de educação financeira no sistema de ensino ocasionou a ampliação da propensão de poupar nos estudantes norte-americanos. Já Braunstein e Welch (2002), embora questionem a qualidade e a eficácia desses programas, não descartam a sua relevância para o bem-estar financeiro dos indivíduos.

\section{Experiência internacional}

As pesquisas sobre educação financeira estão concentradas, majoritariamente, nos Estados Unidos e Reino Unido, sendo focalizadas nos ensinos médio e universitário. A despeito do envelhecimento da população adulta, pouca aten- 
ção vem sendo dada para a capacitação desse grupo. Além disso, grande parte da literatura é voltada para as descrições estatísticas que relacionam dados demográficos, socioeconômicos e financeiros com as iniciativas de educação financeira (Worthington, 2006).

Segundo Holzmann e Miralles (2005), o processo de educação financeira, aparentemente, está mais desenvolvido nos Estados Unidos, Reino Unido, Canadá, Austrália e Nova Zelândia, bem como em alguns países da América Latina e da Europa Central e Oriental, que reformularam o seu sistema previdenciário.

Esses países perceberam a importância do tema e, por conta disso, vêm desenvolvendo uma grande variedade de programas. Para tal, utilizam ferramentas de treinamento - como sites, panfletos e brochuras - , além de se valerem de campanhas na mídia, para esclarecer os indivíduos de assuntos como crédito, seguro, investimento e poupança previdenciária.

No entanto, Lusardi e Mitchell (2007) constataram que, nesses mesmos países, os indivíduos apresentam dificuldades para a elaboração de seu planejamento financeiro, o que implica dificuldades para a fase da aposentadoria e no processo de acumulação de riqueza. Assim, há uma demanda pela educação financeira suprida por iniciativas da esfera privada e de organismos nãogovernamentais, segundo esses mesmos autores.

Assim, reconhecendo a necessidade de se desenvolver a poupança previdenciária e melhorar o entendimento dos indivíduos sobre os produtos financeiros, a Organização para Cooperação e Desenvolvimento Econômico (OCDE) criou o Financial Education Project para estudar a educação financeira e propor programas aos seus países-membros (OCDE, 2004).

O programa foi estabelecido em 2003, com a finalidade de analisar a efetividade das iniciativas existentes nos países, desenvolver técnicas que permitam a comparação dos programas, de modo a prover um conjunto de recomendações de melhores práticas para a sua implantação (Smith, 2005). De acordo com a OCDE, foi publicado um relatório em novembro de 2005 Improving financial literacy: analysis of issues and policies - , apresentando os resultados obtidos. Observou-se que os países pesquisados estão adotando políticas para instruir a população quanto aos conceitos de crédito, de investimentos e de instrumentos de seguro e demonstram preocupação com a população jovem. Entretanto, ainda há obstáculos para o êxito desses programas, em geral, por conta do orçamento necessário para a sua implantação, e da reduzida compreensão da população sobre os benefícios oriundos da educação financeira.

Pesquisas realizadas pela OCDE, nos seus não-membros, originaram recomendações e princípios, enumerados no quadro. 


\section{Princípios e recomendações de educação financeira}

1. A educação financeira deve ser promovida de uma forma justa e sem vieses, ou seja, o desenvolvimento das competências financeiras dos indivíduos precisa ser embasado em informações e instruções apropriadas, livres de interesses particulares.

2. Os programas de educação financeira devem focar as prioridades de cada país, isto é, se adequarem à realidade nacional, podendo incluir, em seu conteúdo, aspectos básicos de um planejamento financeiro, como as decisões de poupança, de endividamento, de contratação de seguros, bem como conceitos elementares de matemática e economia. Os indivíduos que estão para se aposentar devem estar cientes da necessidade de avaliar a situação de seus planos de pensão, necessitando agir apropriadamente para defender seus interesses.

3. 0 processo de educação financeira deve ser considerado, pelos órgãos administrativos e legais de um país, como um instrumento para o crescimento e a estabilidade econômica, sendo necessário que se busque complementar o papel exercido pela regulamentação do sistema financeiro e pelas leis de proteção ao consumidor.

4. 0 envolvimento das instituições financeiras no processo de educação financeira deve ser estimulado, de tal forma que a adotem como parte integrante de suas práticas de relacionamento com seus clientes, provendo informações financeiras que estimulem a compreensão de suas decisões, principalmente nos negócios de longo prazo e naqueles que comprometam expressivamente a renda atual e futura de seus consumidores.

5. A educação financeira deve ser um processo contínuo, acompanhando a evolução dos mercados e a crescente complexidade das informações que os caracterizam.

6. Por meio da mídia, devem ser veiculadas campanhas nacionais de estímulo à compreensão dos indivíduos quanto à necessidade de buscarem a capacitação financeira, bem como 0 conhecimento dos riscos envolvidos nas suas decisões. Além disso, precisam ser criados sites específicos, oferecendo informações gratuitas e de utilidade pública.

7. A educação financeira deve começar na escola. É recomendável que as pessoas se insiram no processo precocemente.

8. As instituições financeiras devem ser incentivadas a certificar que os clientes leiam e compreendam todas as informações disponibilizadas, especificamente, quando forem relacionadas aos negócios de longo prazo, ou aos serviços financeiros, com conseqüências relevantes.

9. Os programas de educação financeira devem focar, particularmente, aspectos importantes do planejamento financeiro pessoal, como a poupança e a aposentadoria, 0 endividamento e a contratação de seguros.

10. Os programas devem ser orientados para a construção da competência financeira, adequando-se a grupos específicos, e elaborados da forma mais personalizada possível.

Fonte: OCDE, 2005. 


\section{Estados Unidos}

Nos Estados Unidos, percebemos uma grande quantidade de sites e instituições envolvidos no processo de educação financeira e, segundo Bernheim, Garrett e Maki (1997), no país, 29 estados - do total de 50 estados e um distrito - entre 1957 e 1985, tornaram a educação financeira obrigatória nas escolas secundárias, com o objetivo de preparar os jovens para a vida adulta. Percebe-se, portanto, a inclusão da educação financeira no sistema de ensino nos Estados Unidos e, também, o envolvimento das instituições governamentais, financeiras e de organizações do terceiro setor.

\section{Instituições governamentais}

O Federal Reserve (Fed) é o Banco Central norte-americano - composto por sete membros do Board of Governors e 12 do Reserve Banks, das principais cidades — criado em dezembro de 1913. De acordo com Fox, Hoffmann e Welch (2004), o Fed vem atuando, de forma ativa, no levantamento de dados sobre a efetividade dos programas de educação financeira, que englobam atividades direcionadas aos trabalhadores, aos estudantes e à população como um todo.

Conforme Worthington (2006), o Fed criou o Jump Coalition for Personal Financial Literacy que, a cada dois anos, avalia o nível de conhecimento financeiro dos estudantes do ensino médio, colaborando na proliferação de leis estaduais que instituem a inserção da educação financeira nas grades curriculares.

O site do Board of Governors contém conceitos referentes à economia e aos serviços bancários, bem como links de outras entidades relacionadas à educação financeira (Federal Reserve Education, 2006). Por meio dos seus programas, o Board of Governors promove eventos, organiza publicações acadêmicas e orienta os indivíduos quanto aos seus direitos (Fox, Hoffmann e Welch, 2004).

O Federal Reserve Bank of Chicago oferece recursos online para pesquisadores, educadores e elaboradores de programas de educação financeira. Já o Federal Reserve Bank of San Francisco possui o Guide to financial literacy resources, que apresenta conceitos básicos de educação financeira e dados úteis para os consumidores. Entre seus projetos, vale destacar os workshops que realiza e a assistência disponibilizada aos pequenos negócios (Fox, Hoffmann e Welch, 2004). O Federal Reserve Bank of Philadelphia disponibiliza um conjunto de informações sobre os materiais disponíveis e instituições que atuam no processo de educação financeira. 
Ainda na esfera governamental, o senado norte-americano vem realizando audiências sobre o assunto, e o Tesouro Nacional fundou o Office of Financial Education, que foca o desenvolvimento da competência financeira (Worthington, 2006).

\section{Instituições financeiras}

Em instituições financeiras como Bank of America, Citibank e Chase, o interesse pelo assunto vem crescendo. Em 2003, por exemplo, cerca de $98 \%$ dos bancos norte-americanos financiaram projetos de educação financeira e $72 \%$ desenvolveram os seus próprios programas, com o intuito de capacitar os jovens, evitando que eles tenham problemas de ordem financeira (Worthington, 2006).

\section{Organizações do terceiro setor}

A National Endowment for Financial Education (Nefe) é um exemplo de entidade sem fins lucrativos cuja finalidade é auxiliar a população na aquisição de informações e no desenvolvimento de competências para a gestão das suas finanças pessoais.

\section{Reino Unido}

No Reino Unido, as principais instituições envolvidas no processo de capacitação financeira são o UK government education departments, o Financial Services Authority (FSA), o Basic Skills Agency (BSA), o Department for Work and Pensions (DWP), o Tesouro Nacional, as instituições financeiras, os grupos comunitários e as escolas (England e Chatterjee, 2005).

\section{UK government education departments}

Nos países que formam o Reino Unido - Inglaterra, País de Gales, Escócia e Irlanda do Norte - a educação financeira é facultativa no currículo escolar desde 2001 e, portanto, não há nenhuma exigência legal para lecioná-la nas escolas. Na Inglaterra, por exemplo, a educação financeira não possui status 
de disciplina regular, sendo os seus conceitos transmitidos em cursos de matemática, educação moral e cívica, entre outros (England e Chatterjee, 2005).

\section{Financial Services Authority}

A Financial Services Authority (FSA) é uma organização não-governamental que atua na proteção dos consumidores, no combate aos crimes financeiros e na divulgação dos conceitos ligados ao funcionamento do sistema financeiro. Vem atuando no sentido de promover a expansão da educação financeira, por meio de projetos que envolvem escolas, jovens, aposentadoria, empréstimos e recomendações financeiras (England e Chatterjee, 2005).

Em 2003, a FSA reuniu líderes industriais e defensores dos direitos dos consumidores para discutir estratégias de educação financeira, recomendações e informações gerais que permitissem a identificação de lacunas a serem supridas na capacitação financeira dos indivíduos (Worthington, 2006).

\section{Basic Skills Agency}

Fundada em 2000, a Basic Skills Agency (BSA) é focada no fomento de programas direcionados à melhoria das técnicas de ensino e de aprendizagem dos adultos (England e Chatterjee, 2005).

\section{Department for Work and Pensions}

O Department for Work and Pensions (DWP) concentra seus esforços no desenvolvimento de políticas de educação financeira voltadas para as instituições de ensino e para os indivíduos à margem desse sistema, de modo a ampliar as aptidões da população, no que tange à interpretação de informações e recomendações de natureza financeira (England e Chatterjee, 2005).

\section{Instituições financeiras e outras associações}

Empresas do setor financeiro, como o Royal Bank of Scotland (RBS), NatWest, Barclays e Lloyds TSB, e entidades comunitárias, como os Services Against 
Financial Exclusion (Safe) e o Pre-Retirement Association atuam no fortalecimento da educação financeira no Reino Unido (England e Chatterjee, 2005).

Também são exemplos de instituições envolvidas com programas de educação financeira, o Personal Finance Education Group - que procura desenvolver competências nos educadores de finanças pessoais - e a Citizens Advice Bureaux que, juntamente com a Stewart Ivory Foundation, fomenta a educação financeira na comunidade em geral (Worthington, 2006).

\section{Outros países}

Holzmann e Miralles (2005) mencionam o estágio da educação financeira em alguns países da OCDE - República Tcheca, Hungria, Polônia e Eslováquia e em outros não-membros - Bulgária, Lituânia, Macedônia e Ucrânia. Em linhas gerais, observamos que há uma incipiência de conhecimento sobre o tema, a mídia é a maior envolvida no processo de capacitação financeira, e tanto os indivíduos quanto as instituições enfrentam dificuldades para se inserir na educação financeira.

Nas últimas décadas, vários fatores contribuíram para a criação de serviços financeiros na Austrália, exigindo maior capacitação financeira dos consumidores para a gestão efetiva do seu patrimônio. Em seu estudo, Worthington (2006) menciona que o nível de conhecimento financeiro é mais elevado entre pessoas de 50 a 60 anos, profissionais, empresários, donos de fazenda e indivíduos com formação universitária. Menor nível é observado nos desempregados, mulheres e aqueles que não falam inglês, com reduzido grau de educação.

\section{Educação financeira no Brasil}

No caso brasileiro, não foram encontrados trabalhos que consolidam as informações sobre educação financeira. Isso torna este artigo extremamente relevante, já que se trata de uma contribuição institucional para futuras discussões sobre o tema no país.

Com esse intuito, foi realizado um levantamento das principais ações desenvolvidas pelos órgãos governamentais, instituições financeiras e de ensino, associações e mídia, no que tange ao processo de educação financeira. Não pretendemos, com esses dados, esgotar o assunto, mas sim ilustrar a sua evolução no país. Vale ressaltar, ainda, que tais ações são insuficientes para atender a demanda por esses conhecimentos. 


\section{Ministério da Educação e Cultura (MEC)}

Não há obrigatoriedade da educação financeira no sistema de ensino. O MEC preconiza a contextualização do ensino, que pressupõe um processo de aprendizagem apoiado no desenvolvimento de competências para inserção dos estudantes na vida adulta, mediante a multidisciplinaridade, o incentivo do raciocínio e da capacidade de aprender.

No ensino de matemática, recomenda-se estimular: a capacidade de leitura e interpretação de textos com conteúdo econômico; a habilidade de análise e julgamento dos cálculos de juros nas vendas a prazo; a compreensão do relacionamento entre a matemática e os demais campos de conhecimento, como a economia; a utilização desta para promover ações de defesa dos direitos do consumidor (MEC, 2000a, 2000b).

Tais orientações são oriundas da Lei de Diretrizes e Bases da Educação Nacional (no 9.384/96), mas não demonstram uma preocupação explícita do MEC com a inserção da educação financeira no ensino.

O MEC, em conjunto com o Ministério da Fazenda, a Secretaria da Receita Federal, a Secretaria do Tesouro Nacional, e as secretarias da Fazenda e de Educação dos estados, vem implementando o Programa Nacional de Educação Fiscal, com o objetivo de capacitar os indivíduos no âmbito fiscal. Por meio da Escola de Administração Fazendária (Esaf) são oferecidos cursos online e materiais sobre o assunto (Esaf, 2006).

\section{Universidades}

Não verificamos uma participação constante das instituições de ensino superior no processo de educação financeira.

\section{Banco Central do Brasil (Bacen)}

O Bacen possui o Programa de Educação Financeira (PEF), responsável pela orientação da sociedade a respeito de assuntos econômicos, contribuindo para um melhor entendimento dos aspectos financeiros e da responsabilidade no planejamento das finanças pessoais. São exemplos de ações implementadas (Bacen, 2006):

v Projeto Museu-Escola, que envolve visitas monitoradas ao museu do Bacen;

- Projeto o Museu Vai à Escola, que é uma extensão do Projeto Museu-Esco- 
la, levando palestras e exposições às escolas do Distrito Federal e de regiões próximas;

v Projeto BC e Universidade, composto por palestras mensais, ministradas por servidores do Bacen e direcionadas aos estudantes universitários, esclarecendo sua atuação e suas funções.

No entanto, percebemos que tais ações empreendidas pelo Bacen não atingem, de forma ampla, o público adulto, que é o principal usuário dos serviços financeiros. Além disso, identifica-se uma lacuna na atuação desse órgão, evidenciada pela inexistência de uma regulamentação que exija o fomento da educação financeira por parte de bancos e outras instituições.

\section{Comissões de Valores Mobiliários (CVM)}

Promove palestras e disponibiliza cartilhas gratuitas de educação ao investidor, além de esclarecer dúvidas dos indivíduos quanto a investimentos (CVM, 2006).

\section{Bolsa de Valores de São Paulo (Bovespa)}

Possui o programa educacional Bovespa, criado em 1989, para atender aos interessados que desejam conhecer a bolsa e o funcionamento do mercado acionário. Suas iniciativas buscam evidenciar a importância das bolsas de valores para a economia do país, transmitir conceitos econômicos básicos, estimular hábitos de poupança, entre outras.

Além disso, promove visitas monitoradas à Bolsa; realiza palestras e orientações à população, por meio dos projetos Educar e Bovespa Vai até Você; realiza concursos estudantis; apóia concursos de simulação de investimentos em conjunto com o jornal Folha de S. Paulo; e desenvolve parcerias com instituições de ensino para distribuição de materiais (Bovespa, 2006).

\section{Federação Brasileira de Bancos (Febraban)}

Oferece informações sobre o uso de produtos financeiros, como cartão, caixa automático, segurança e relacionamento com bancos (Febraban, 2006). 


\section{Serasa}

Desenvolveu o Guia Serasa de orientação ao cidadão, que auxilia na gestão dos recursos financeiros e pode ser encontrado em seu site (Serasa, 2006).

\section{Associação Nacional dos Bancos de Investimento (Anbid)}

Difunde conceitos sobre investimento pessoal, estimulando a formação do investidor no Brasil, e incentiva a produção de estudos acadêmicos sobre o mercado de capitais brasileiro. No seu portal <www.comoinvestir.com.br $>$, disponibiliza serviços de e-learning e oferece informações educativas sobre alternativas de investimentos, como: fundos, ações, debêntures, CDB, títulos públicos. Também promove cursos e atua na certificação de profissionais que têm contato com os clientes, ao comercializarem produtos de investimento (Anbid, 2006).

\section{Instituições financeiras}

Poucas instituições financeiras possuem programas de educação financeira para o público. Como exemplo, pode-se citar o Banco Itaú, que disponibiliza o Guia do crédito consciente, orientando os indivíduos no uso apropriado de empréstimos e financiamentos e disponibilizando conceitos para a elaboração de um orçamento familiar (Banco Itaú, 2006).

\section{Mídia e eventos}

No caso brasileiro, o papel exercido pela mídia - jornais, revistas, televisão, rádio e internet - é muito relevante, pela amplitude de seu alcance e pela facilidade de assimilação do conteúdo difundido.

Outra forma de divulgação se dá pela realização de eventos. O Expomoney, por exemplo, oferece palestras gratuitas em São Paulo, Rio de Janeiro e Belo Horizonte, abordando assuntos, como: planejamento financeiro, previdência, fundos de investimento, ações, economia doméstica, entre outros (Expomoney, 2006).

\section{Demais associações}

Podem ser citadas: a Associação Brasileira de Empresas de Cartões de Crédito e Serviços (Abecs), que oferece recomendações por meio do Manual do porta- 
dor de cartão (Abecs, 2006); e a Associação Nacional da Previdência Privada (Anapp), que disponibiliza informações relativas aos produtos de previdência (Anapp, 2006).

\section{Considerações finais}

O objetivo do presente artigo foi discutir a educação financeira no Brasil, de forma a avaliar o estágio das ações referentes ao assunto no contexto nacional, e sugerir iniciativas para o seu fomento. Também pretendemos encorajar o seu desenvolvimento e alertar os agentes envolvidos no processo.

O trabalho iniciou-se com a contextualização e a importância da educação financeira. Prosseguiu com as definições e as experiências internacionais. Discorreu sobre o tratamento do assunto nos Estados Unidos, no Reino Unido e em outros países-membros da OCDE. Em seguida, apresentou as implicações do papel do governo brasileiro para o fomento da educação financeira e, finalmente, retratou as iniciativas existentes no país.

A educação financeira no Brasil se encontra em estágio de desenvolvimento inferior aos Estados Unidos e Reino Unido. No primeiro, o tema é adotado obrigatoriamente na grade de ensino de alguns estados, $72 \%$ dos bancos promovem programas de educação financeira, além de diversas organizações engajadas nesse processo. No Reino Unido, embora seja facultativa, há um forte envolvimento dos atores do processo, inclusive com a criação de um fundo, com o intuito de estimular a cultura de poupança. A explicação para essas diferenças entre o Brasil e os países citados está na compreensão de fatores históricos, culturais, bem como da responsabilidade das instituições no processo de educação financeira.

O extenso período de inflação comprometeu a capacidade de planejamento econômico-financeiro de longo prazo. Com a abertura econômica, no início dos anos 1990, e o processo de estabilização do Plano Real, o mercado financeiro nacional se transformou e criou novos instrumentos, aumentando a complexidade dos produtos oferecidos. Desse modo, os indivíduos e as famílias passaram a demandar maior conhecimento e informação atualizada, para tomarem as suas decisões financeiras de forma fundamentada e segura.

Apesar dessas mudanças, a educação financeira não foi agregada, de maneira oficial, nas grades curriculares e, nas universidades, não se constata uma ação efetiva e duradoura. Tal realidade reflete uma atuação ainda insuficiente do MEC, no que tange à inserção do tema em todos os níveis de ensino.

Assim como no ensino, também não se verifica o desenvolvimento de programas de educação financeira nos bancos brasileiros. As iniciativas exis- 
tentes são escassas e não atendem às demandas dos seus clientes. A regulação da matéria pelo Banco Central pode ser uma alternativa para solucionar tal deficiência.

Outros organismos ligados ao governo - CVM, Ministério da Fazenda, Secretaria da Receita Federal, Secretaria do Tesouro Nacional, Secretaria da Fazenda e secretarias de Educação dos estados — possuem projetos na área de educação financeira, mas ainda estão muito aquém do necessário para habilitar a população adulta sobre o tema.

Diante desse quadro, algumas ações podem ser sugeridas:

incentivar a cultura de poupança na população;

v inserir a educação financeira nos programas de todos os níveis de ensino;

v desenvolver os conceitos de crédito, investimento e consumo por meio de escolas, universidades, mídia e outros setores;

- promover a coordenação de esforços entre governo e sociedade;

v monitorar a qualidade dos programas.

No Brasil, há uma situação preocupante no âmbito da educação financeira, demandando urgência na inserção do tema em todas as esferas, ainda mais considerando a desequilibrada distribuição de renda desse país, onde representativa parte dos recursos produtivos é direcionada ao Estado, tornando imprescindível a excelência na gestão de recursos escassos por parte dos indivíduos e de suas famílias. Além de ser necessária uma coordenação maior de esforços e monitoramento das iniciativas do setor privado, o papel do setor público será de extrema importância para a propagação, fortalecimento e consolidação duradoura da educação financeira, sendo a participação das escolas e das universidades de grande relevância para o seu êxito.

\section{Referências bibliográficas}

ABECS (Associação Brasileira das Empresas de Cartões de Crédito e Serviços). Manual do portador de cartão. Disponível em: <www.abecs.org.br/>. Acesso em: maio 2006.

ANAPP (Associação Nacional da Previdência Privada). Disponível em: <www.anapp. com.br> . Acesso em: maio 2006.

ANBID (Associação Nacional dos Bancos de Investimentos). Disponível em: <www.como investir.com.br>. Acesso em: maio 2006. 
BACEN (Banco Central do Brasil). Programa de Educação Financeira. Disponível em: $<$ www.bacen.gov.br/?PEF-BC > . Acesso em: maio 2006.

BANCO ITAÚ. Guia do crédito consciente. Disponível em: <www.itau.com.br/indexIE.htm>. Acesso em: maio 2006.

BANK OF AMERICA (Bofa). Financial education and tools. Disponível em: $<$ www.bankofamerica.com/financialtools/>. Acesso em: maio 2006.

BASIC SKILLS AGENCY (BSA). About us. Disponível em: <www.money-bsa.org.uk/site/ page.php? $\mathrm{cms}=8 \& \mathrm{p}=2>$. Acesso em: maio 2006 .

BERNHEIM, D. Financial illiteracy, education, and retirement savings. In: MITCHEL, O.; SCHIEBER, S. Living with defined contribution plans. Philadelphia: University of Pennsylvania Press, 1998. p. 38-68.

; GARRETT, D. M. The effects of financial education in the workplace: evidence from a survey of households. Journal of Public Economics, v. 87, p. 1487-1519, 2003.

; _ _ _ MAKI, D. M. Education and saving: the long term effects of high school financial curriculum mandates. National Bureau of Economic Research, n. 6.085, July 1997. Disponível em: <http://www.nber.org/papers/W6085>. Acesso em: maio 2006.

BOLSA DE VALORES DE SÃO PAULO (Bovespa). Programa educacional Bovespa. Bovespa, 2006. Disponível em: <www.bovespa.com.br>. Acesso em: maio 2006.

BRAUNSTEIN, S.; WELCH, C. Financial literacy: an overview of practice, research, and policy. Federal Reserve Bulletin, Nov. 2002.

CHASE. Financial education library. Chase, 2006. Disponível em: <www.chase.com/cm/ cs?pagename $=$ Chase $/$ Href\&urlname $=$ shared $/ \mathrm{crb} /$ page $/$ financial_education_main.jsp $>$. Acesso em: maio 2006.

CITIGROUP. Citigroup Financial Education Program. Citigroup, 2006. Disponível em: $<$ www.citigroup.com/citigroup/financialeducation/>. Acesso em: maio 2006.

CLARK, R. L. et al. Retirement plans and saving decisions: the role of information and education. Journal of Pension Economics and Finance, v. 5, n. 1, Mar. 2006.

COMISSÃO DE VALORES MOBILIÁRIOS (CVM). Disponível em: <www.cvm.gov.br/>. Acesso em: maio de 2006.

DOLVIN, S. D.; TEMPLETON, W. K. Financial education and asset allocation. Financial Services Review, v. 15, n. 3, p. 133, Summer 2006.

ENGLAND, J.; CHATTERJEE, P. Financial education: a review of existing provision in the UK. UK: Department for Work and Pensions, 2005. Disponível em: <www.dwp.gov.uk/ asd/asd5/rports2005-2006/rrep275.pdf>. Acesso em: maio 2006. 
ESAF (Escola de Administração Fazendária). Disponível em: <www.esaf.fazenda.gov.br/ parcerias/educacao-fiscal2/home-educacao-fiscal.html>. Acesso em: maio 2006.

EXPOMONEY. Disponível em: <www.expomoney.com.br/>. Acesso em: maio 2006.

FEBRABAN (Federação Brasileira de Bancos). Disponível em: <www.febraban.org.br/>. Acesso em: maio 2006.

FEDERAL RESERVE BANK OF CHICAGO. Disponível em: <www.chicagofed.org/cedric/ financial_education_research_center.cfm>. Acesso em: maio 2006.

FEDERAL RESERVE BANK OF PHILADELPHIA. Disponível em: <www.phil.frb.org/ consumers >. Acesso em: maio 2006.

FEDERAL RESERVE BANK OF SAN FRANCISCO. Guide to financial literacy resources. Disponível em: <www.frbsf.org/community/webresources/bankersguide.pdf>. Acesso em: maio 2006.

FEDERAL RESERVE EDUCATION. Disponível em: <www.federalreserveeducation.org/ fined/index.cfm > . Acesso em: maio 2006.

FOX, J.; BARTHOLOMAE, S.; LEE, JINKOOK. Building the case for financial education. The Journal of Consumer Affairs, v. 39, n. 1, p. 195, Summer 2005.

FOX, L.; HOFFMANN, J.; WELCH, C. Federal reserve personal financial education initiatives. Federal Reserve Bulletin, Autumn, 2004. Disponível em: <www.federalreserve.gov/pubs/ bulletin/2004/autumn04_fined.pdf >. Acesso em: maio 2006.

HOLZMANN, R.; MIRALLES, M. P. The role, limits of, and alternatives to financial education in support of retirement saving in the OECD, Eastern Europe and beyond. The World Bank, Oct. 2005. Disponível em: <http://info.worldbank.org/etools/library/view_p.asp?2057 15>. Acesso em: maio 2006.

LUSARDI, A.; MITCHELL, O. S. Financial literacy and retirement preparedness: evidence and implications for Financial Education Programs. Pension Research Council Working Paper. Jan. 2007.

MANDELL, L. Financial literacy: Does it matter? New York: University at Buffalo, Apr. 2005. MEC (Ministério da Educação). Parâmetros curriculares nacionais: ensino médio. 2000a.

. PCN ensino médio: orientações educacionais complementares aos parâmetros curriculares nacionais, ciências da natureza, matemática e suas tecnologias. 2000b.

NEFE (National Endowment for Financial Education). Disponível em: <www.nefe.org/ pages/contents.html>. Acesso em: maio 2006. 
OCDE (Organização de Cooperação e de Desenvolvimento Econômico). OECD's Financial Education Project. Assessoria de Comunicação Social, 2004. Disponível em: <www.oecd.org/ >. Acesso em: março 2006.

. Recommendation on principles and good practices for financial education and awareness. July 2005. Disponível em: <www.oecd.org/>. Acesso em: mar. 2006.

SERASA. Disponível em: <www.serasa.com.br/guia/conteudo.htm>. Acesso em: maio 2006.

SMITH, B. OECD's Financial Education Project: improving financial literacy and capability. In: CANADIANS AND THEIR MONEY: A NATIONAL SYMPOSIUM ON FINANCIAL CAPABILITY. Proceedings... Ottawa, June 2005. Disponível em: < http://policyresearch.gc.ca/ doclib/FCAC/Session\%205\%20Barbara\%20Smith.pdf>. Acesso em: maio 2006.

VOLPE, R.; CHEN, H.; LIU, S. An analysis of the importance of personal finance topics and the level of knowledge possessed by working adults. Financial Services Review, v. 15, p. 8198, 2006.

TODD, R. M. Financial literacy education: a potencial tool for reducing predatory lending? Federal Reserve Bank of Minneapolis - The Region, v. 16, p. 6-13, Dec. 2002.

WORTHINGTON, A. C. Predicting financial literacy in Australia. Financial Services Review, v. 15, n. 1, p. 59-79, Spring 2006. 